\title{
Proximal Region of Carotid Atherosclerotic Plaque Shows More Intraplaque Hemorrhage: The Plaque at Risk Study
}

\author{
(D) G.A.J.C. Crombag, (D) M. Aizaz, (D)F.H.B.M. Schreuder, (D)F. Benali, (DD.H.K. van Dam-Nolen, (D) M.I. Liem, (D). Lucci, \\ (D) A.F. van der Steen, (D).J.A.P. Daemen, (D)W.H. Mess, (D) A. van der Lugt, (DP.J. Nederkoorn, (D). Hendrikse, (DP.A.M. Hofman, \\ (D) R.J. van Oostenbrugge, (D).E. Wildberger, and (D) M.E. Kooi
}

\begin{abstract}
BACKGROUND AND PURPOSE: Intraplaque hemorrhage contributes to lipid core enlargement and plaque progression, leading to plaque destabilization and stroke. The mechanisms that contribute to the development of intraplaque hemorrhage are not completely understood. A higher incidence of intraplaque hemorrhage and thin/ruptured fibrous cap (upstream of the maximum stenosis in patients with severe $[\geq 70 \%$ ] carotid stenosis) has been reported. We aimed to noninvasively study the distribution of intraplaque hemorrhage and a thin/ruptured fibrous cap in patients with mild-to-moderate carotid stenosis.
\end{abstract}

MATERIALS AND METHODS: Eighty-eight symptomatic patients with stroke ( $<70 \%$ carotid stenosis included in the Plaque at Risk study) demonstrated intraplaque hemorrhage on MR imaging in the carotid artery plaque ipsilateral to the side of TIA/stroke. The intraplaque hemorrhage area percentage was calculated. A thin/ruptured fibrous cap was scored by comparing pre- and postcontrast black-blood TSE images. Differences in mean intraplaque hemorrhage percentages between the proximal and distal regions were compared using a paired-samples $t$ test. The McNemar test was used to reveal differences in proportions of a thin/ruptured fibrous cap.

RESULTS: We found significantly larger areas of intraplaque hemorrhage in the proximal part of the plaque at 2, 4, and $6 \mathrm{~mm}$ from the maximal luminal narrowing, respectively: $14.4 \%$ versus $9.6 \%(P=.04), 14.7 \%$ versus $5.4 \%(P<.001)$, and $11.1 \%$ versus $2.2 \%(P=.001)$. Additionally, we found an increased proximal prevalence of a thin/ruptured fibrous cap on MR imaging at 2, 4, 6, and $8 \mathrm{~mm}$ from the MR imaging section with the maximal luminal narrowing, respectively: $33.7 \%$ versus $18.1 \%, P=.007 ; 36.1 \%$ versus $7.2 \%, P<.001$; $33.7 \%$ versus $2.4 \%, P=.001$; and $30.1 \%$ versus $3.6 \%, P=.022$.

CONCLUSIONS: We demonstrated that intraplaque hemorrhage and a thin/ruptured fibrous cap are more prevalent on the proximal side of the plaque compared with the distal side in patients with mild-to-moderate carotid stenosis.

ABBREVIATIONS: FC = fibrous cap; IPH = intraplaque hemorrhage; QIR TSE = quadruple inversion recovery turbo spin-echo; TRFC = thin/ruptured fibrous cap

$\mathbf{R}$ upture of a vulnerable atherosclerotic plaque is an important underlying cause of myocardial infarction and stroke. ${ }^{1}$ Noninvasive visualization of plaque vulnerability has demonstrated that intraplaque hemorrhage (IPH) contributes to enlargement of the lipid core and plaque progression, leading to plaque destabilization. ${ }^{2,3}$ Indeed, we and others have

Received July 20, 2021; accepted after revision October 14.

From the Departments of Radiology and Nuclear Medicine (G.A.J.C.C., M.A., F.B., P.A.M.H., J.E.W., M.E.K.), Clinical Neurophysiology (W.H.M.), and Neurology (R.J.v.O.), Maastricht University Medical Center, Maastricht, the Netherlands; CARIM School for Cardiovascular Diseases (G.A.J.C.C., M.A., R.J.v.O., J.E.W., M.E.K.), Maastricht University, Maastricht, the Netherlands; Department of Neurology \& Donders Institute for Brain Cognition \& Behaviour (F.H.B.M.S.), Radboud University Medical Center, Nijmegen, the Netherlands; Departments of Radiology and Nuclear Medicine (D.H.K.v.D.-N., A.v.d.L.) and Biomedical Engineering (A.F.v.d.S.), Erasmus University Medical Center, University Medical Center Rotterdam, Rotterdam, the Netherlands; and Departments of Neurology (M.I.L., P.J.N.) and Pathology (M.J.A.P.D.), Amsterdam University Medical Centres, University of Amsterdam, Amsterdam, the Netherlands; and Department of Radiology (C.L., J.H.), University Medical Center Utrecht, Utrecht, the Netherlands. demonstrated that IPH on MR imaging is a strong predictor of future cerebrovascular events. ${ }^{4-6}$ This finding has led to the recognition of IPH as a key marker and pathologic factor contributing to plaque vulnerability.

This work was supported by the Center for Translational Molecular Medicine (www. ctmm.nl), project PARISK (grant 01C-202), and the Netherlands Heart Foundation. This project has received funding from the European Union Horizon 2020 research and innovation program under the Marie Skłodowska-Curie grant agreement No 722609. M.E. Kooi is supported by an Aspasia Grant 2018/SGw/00460457 from Nederlandse Organisatie voor Wetenschappelijk Onderzoek. J. Hendrikse received funding from the European Research Council under the European Union's Horizon 2020 program (H2020)/European Research Council grant agreement No. 637024. F.H.B.M. Schreuder is supported by the Netherlands Heart Foundation (2019T060).

Please address correspondence to M. Eline Kooi, MD, Department of Radiology and Nuclear Medicine, Maastricht University Medical Centre, PO Box 5800, 6202 AZ Maastricht, the Netherlands; e-mail: eline.kooi@mumc.nl

- Indicates open access to non-subscribers at www.ajnr.org

三 Indicates article with online supplemental data.

http://dx.doi.org/10.3174/ajnr.A7384 
However, the underlying mechanisms of IPH development are not completely understood. Most often, leakage of erythrocytes from intraplaque microvessels is proposed as a cause for IPH. ${ }^{7,8}$ In contrast, we recently observed fewer microvessels in plaques with $\mathrm{IPH}^{9}{ }^{9}$ suggesting that damage to the plaque luminal surface such as fissures and rupture of the fibrous cap (FC) could contribute to IPH. ${ }^{8,10}$ It was demonstrated in histologic specimens that IPH occurs more frequently in the proximal part of the plaque, ${ }^{11,12}$ where the biomechanical wall stress is usually higher, ${ }^{13-16}$ due to arterial pressure wave reflection. In a histopathologic study, we demonstrated that IPH occurred in regions with FC fissures and juxtaluminal calcifications. Juxtaluminal calcifications may lead to increased biomechanical wall stress. ${ }^{17}$ Fissures were found in 58\% of plaques with grossly intact luminal surfaces. Most of the fissures (88\%) occurred in the proximal region of the plaque. The fissures were connected to IPH (92\%) and calcifications (43\%), while they were connected to microvessels in only $25 \%$ of cases. ${ }^{17}$

Previous histologic studies were dependent on patient populations that underwent carotid endarterectomy, usually patients with severe carotid stenosis. MR imaging allows investigation of carotid plaques, even in patients with a lower grade of stenosis in which the arterial pressure wave reflection will be less severe. ${ }^{18-20}$

This study aimed to investigate, noninvasively, whether there is a difference in volume of IPH and the status of the FC in the proximal-versus-distal regions in a relatively large group of patients with stroke with mild-to-moderate carotid stenosis and IPH.

\section{MATERIALS AND METHODS \\ Study Design}

Baseline MR imaging data were analyzed from patients included in the Plaque at Risk (PARISK) study that demonstrated IPH. PARISK is a large, prospective, multicenter cohort study investigating whether plaque imaging enables us to better identify patients with carotid stenosis who have an increased stroke risk. ${ }^{21}$ Patients with a recent ( $<3$ months) TIA or ischemic stroke in the anterior circulation and carotid artery plaque of $>2 \mathrm{~mm}$ but $<70 \%$ stenosis ipsilateral to the side of TIA/stroke were prospectively included. The degree of stenosis was determined with Doppler sonography or with CTA. An upper cutoff value of $70 \%$ was used on the basis of the NASCET criteria. ${ }^{22}$ Institutional medical ethical committee approval was obtained, and all patients provided written informed consent.

\section{MRI}

The MR imaging protocol has been described in detail previously. $^{21}$

In brief, multisequence carotid MR imaging was performed on a $3 \mathrm{~T}$ whole-body scanner (Achieva or Ingenia, Philips Healthcare, or Discovery MR 750, GE Healthcare). A dedicated 8-channel phased-array coil (Shanghai Chenguang Medical Technologies) or a 4-channel carotid coil (PACC-ST30, Machnet B.V. Roden, the Netherlands) was used. Dedicated vessel wall image-analysis software (VesselMass; Leiden University Medical Center, the Netherlands) was used to analyze the MR images of the ipsilateral carotid plaque. After an extensive training period and demonstrating good interobserver agreement with a validation set that was previously delineated in consensus by experts (with $>7$ and $>10$ years of experience, respectively), the trained observers

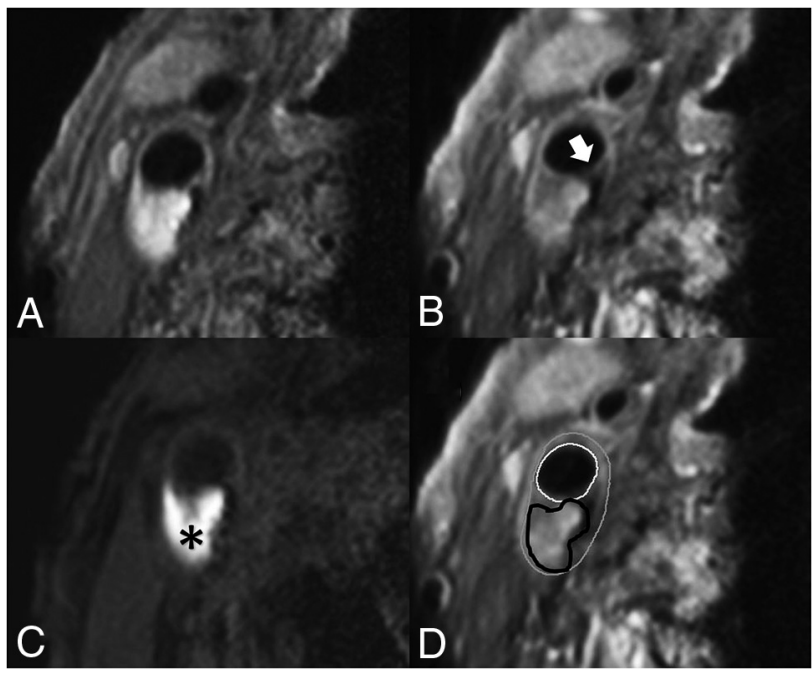

FIG 1. Transversal MR images of carotid plaque in the right carotid artery. We acquired the following MR images: precontrast T1-weighted QIR TSE (A), postcontrast T1-weighted QIR TSE (B), T1-weighted inversion recovery turbo field echo (C). $D$, The same image as in $B$, including the contours delineating intraplaque hemorrhage and the inner and outer vessel wall: white $=$ lumen, gray $=$ outer vessel wall, black = intraplaque hemorrhage. C, A hyperintense signal in the bulk of the plaque can be clearly observed, indicating the presence of intraplaque hemorrhage (black asterisk). B, An interruption of the signal enhancement adjoining the lumen can be observed, indicating a TRFC (white arrow).

manually delineated the outer vessel wall, luminal area, and plaque components as previously described. ${ }^{23}$ Image quality was rated on a 5-point scale. ${ }^{24}$ Patients were excluded if the mean image quality score was $<2$.

The vessel wall and luminal area were delineated on the precontrast T1-weighted double inversion recovery FSE images (center 2) or the quadruple inversion recovery turbo spin-echo (QIR TSE) (center 1, 3, and 4) images. IPH delineation was performed on T1-weighted inversion recovery turbo field echo images (center 1,3, and 4) or 3D T1-weighted fat-suppressed spoiled gradient-echo images (center 2).

IPH was delineated by visual observation and was defined as hyperintense signal within the bulk of the plaque compared with the adjacent sternocleidomastoid muscle and was manually delineated per section by the trained observers. FC status was dichotomized as thick versus thin or ruptured. ${ }^{25}$ When a continuous signal enhancement on the postcontrast images between the lipid rich necrotic core and the lumen was identified, the FC status was classified as "intact and thick." When no or an interrupted area of enhancement was identified, the FC status was classified as "thin and/or ruptured." In slices without a lipid rich necrotic core, there is no interrupted area of signal enhancement; therefore, the status of the FC is scored by definition as "intact and thick" (Fig 1).

Previously, we have shown that our method of scoring IPH demonstrated good agreement between MR imaging and histology. ${ }^{26}$ Interobserver reproducibility for the detection of IPH was very good $(\kappa=0.86)$. We also demonstrated an overall very good interobserver reproducibility of MR image analysis (for carotid 


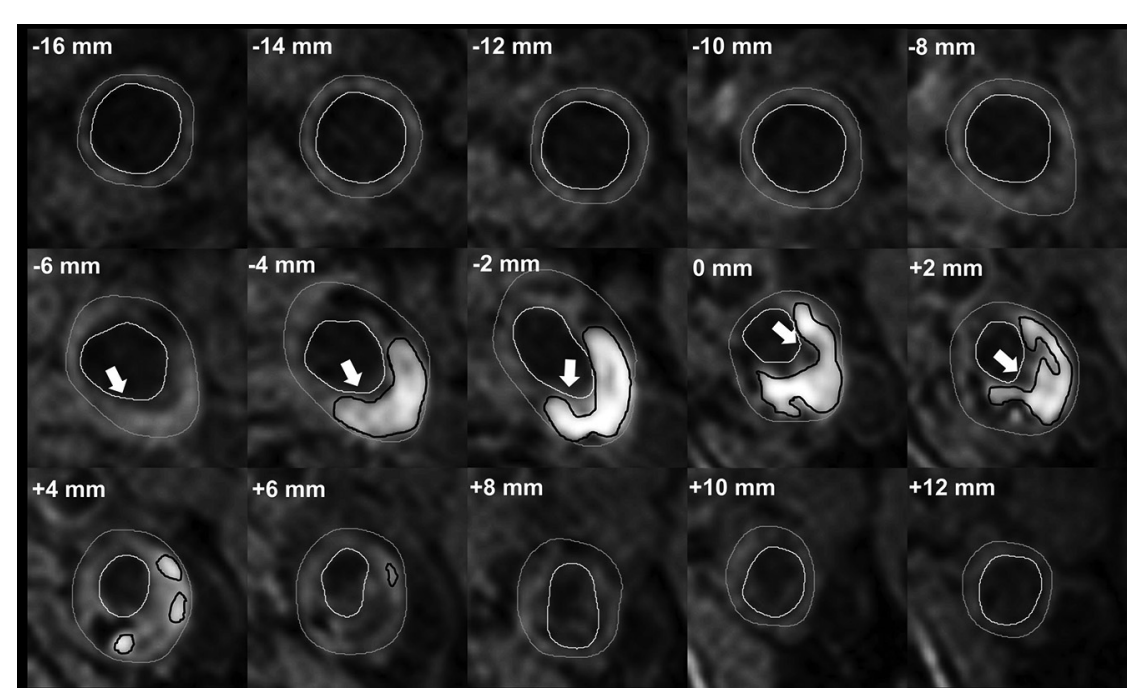

FIG 2. A patient's dataset acquired with an inversion recovery turbo field echo sequence. Delineation of the inner and outer vessel walls and IPH in every 2-mm-thick MR imaging section proximal and distal to the section with the narrowest lumen $(0 \mathrm{~mm})$. Gray outline = outer vessel wall, white outline $=$ inner vessel wall, black outline $=\mathrm{IPH}$, white arrow $(-6 \mathrm{~mm}$ to $+2 \mathrm{~mm})=\mathrm{MR}$ imaging slices in which the FC status is scored as thin or ruptured. The status of the FC was determined by using the postcontrast TI-weighted QIR TSE sequence. There is a larger volume of IPH at the proximal side of the section with the narrowest lumen $(0 \mathrm{~mm})$, and most of the slices with a TRFC cap are also located at the proximal side.

lumen volume, wall volume, and total vessel volume: intraclass correlation coefficient/coefficient of variation $=0.96 / 7.7 \%, 0.95 /$ $8.8 \%$, and $0.92 / 12.8 \%$, respectively). ${ }^{27}$ Interobserver reproducibility of FC status assessment was good $(\kappa=0.60-0.71) .{ }^{28}$ Also, we have previously shown a very good overall interscan/intraobserver reproducibility in a study in which patients were scanned twice within a mean of $4(\mathrm{SD}, 2.9)$ days (for carotid lumen volume and wall volume: intraclass coefficient/coefficient of variation $=0.99$ / $7.2 \%$ and $0.99 / 7.1 \%$, respectively). ${ }^{27}$ The interscan/intraobserver reproducibility for the detection of IPH and FC status were very good $(\kappa=1.00) .^{27}$ On the basis of these delineations, the dedicated vessel wall imaging software package automatically calculates the luminal and vessel wall area and the areas of each plaque component per section. Using the vessel wall and IPH areas, we calculated the percentage of IPH of the total vessel wall area per section. Starting at the section with the narrowest lumen, the IPH area and the presence of a thin/ruptured fibrous cap (TRFC) were determined for the neighboring proximal and distal slices at an interval of $2 \mathrm{~mm}$ (ie, the MR imaging section thickness) (Fig 2).

\section{Plaque Composition in Proximal-versus-Distal Regions}

The proximal region of the plaque is defined as the region proximal to the imaging section with the narrowest lumen (lumen with the absolute lowest area based on luminal contour). The vessel wall area was calculated for each MR imaging section. We generated a histogram of the distribution of the mean IPH area percentage. In addition, we also calculated differences in absolute areas of IPH between the proximal and distal parts of the plaque. The distribution of MR imaging slices with a TRFC at each MR imaging section position proximal and distal to the MR imaging section with the narrowest lumen was also assessed. Section positions with data from $<25$ patients are excluded in these histograms because of the small statistical power.

\section{Statistical Analyses}

Statistical analyses were performed using SPSS 24.0 (IBM). A $P$ value $<.05$ was considered statistically significant. To analyze the differences between proximal and distal areas of IPH, we used a paired $t$ test to compare the slices proximal $(-n)$ and distal $(+n)$ to the section with the narrowest lumen (ie, Section 0 ). The paired $t$ test was also used to test the overall difference in absolute IPH area between the proximal and distal regions. A McNemar test was used to analyze differences in proportions of the FC status between the proximal and distal slices, per section and overall per patient.

\section{RESULTS}

Of 244 included patients, 6 patients withdrew from the study. Of the remaining 238 patients, another 14 patients were excluded due to bad quality scores of the MR imaging $(n=4)$, incomplete MR imaging protocol $(n=2)$, or absence of MR imaging data due to claustrophobia $(n=6)$ or obesity $(n=2)$. Of the remaining 224 patients, 88 patients (39\%) demonstrated IPH on the ipsilateral side. Baseline patient characteristics are shown in the Online Supplemental Data. For the analysis of the FC status, another 5 patients were excluded because no postcontrast MR imaging was available (Online Supplemental Data).

The mean IPH area percentage was significantly larger in the proximal part of the plaque (Fig $3 A$ ). The largest mean IPH area percentage is observed $4 \mathrm{~mm}$ proximal to the narrowest lumen. The proximal-versus-distal area percentages of IPH are at 2, 4, and $6 \mathrm{~mm}$ from the narrowest lumen, respectively: $14.4 \%$ versus $9.6 \%$ $(P=.04), 14.7 \%$ versus $5.4 \%(P<.001)$, and $11.1 \%$ versus $2.2 \%$ $(P=.001)$. The MR images at 8 and $10 \mathrm{~mm}$ from the narrowest lumen also show a higher mean area percentage of IPH proximal compared with distal; however, this difference was not significant (7.5\% versus $2.2 \%, P=.056 ; 5 \%$ versus $1.1 \%, P=.077$ ) (Table 1 ). Also, the absolute IPH area in the proximal region was significantly higher compared with the distal region at 2, 4, 6, 8, and $10 \mathrm{~mm}$ from the narrowest lumen, respectively $\left(0.11\right.$ versus $0.07 \mathrm{~cm}^{2}$, $P=.019 ; 0.12$ versus $0.04 \mathrm{~cm}^{2}, P<.001 ; 0.10$ versus $0.01 \mathrm{~cm}^{2}$, $P<.001 ; 0.06$ versus $0.01 \mathrm{~cm}^{2}, P=.005$; and 0.03 versus 0.0003 $\left.\mathrm{cm}^{2}, P=.004\right)$.

In these patients with IPH, 76\% demonstrated a TRFC. The proximal region of the plaque in patients with IPH showed a higher prevalence of a TRFC compared with the distal region at $2,4,6$, and $8 \mathrm{~mm}$ from the MR imaging section with the narrowest lumen, respectively: $33.7 \%$ versus $18.1 \%, P=.007 ; 36.1 \%$ versus $7.2 \%, P<.001 ; 33.7 \%$ versus $2.4 \%, P=.001$; and $30.1 \%$ versus $3.6 \%, P=.022$. At $10 \mathrm{~mm}$ from the narrowest lumen, the 


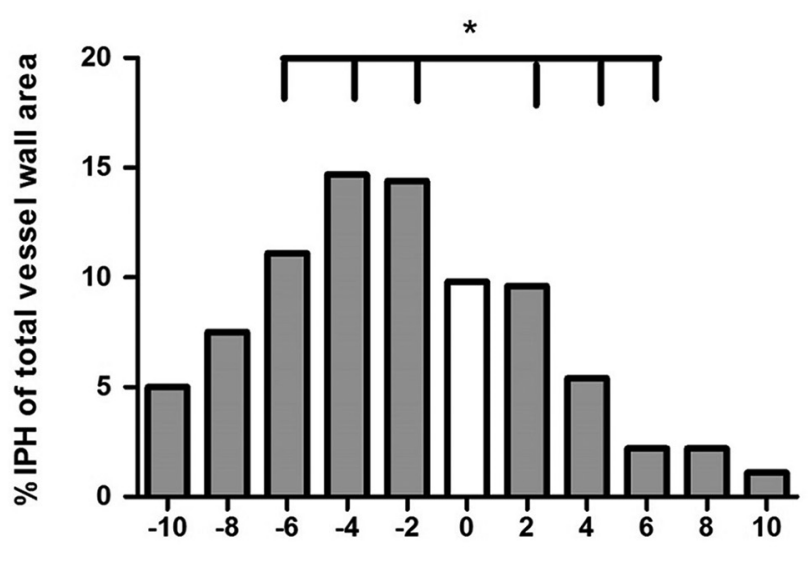

A

Distance to maximal stenosis $(\mathrm{mm})$

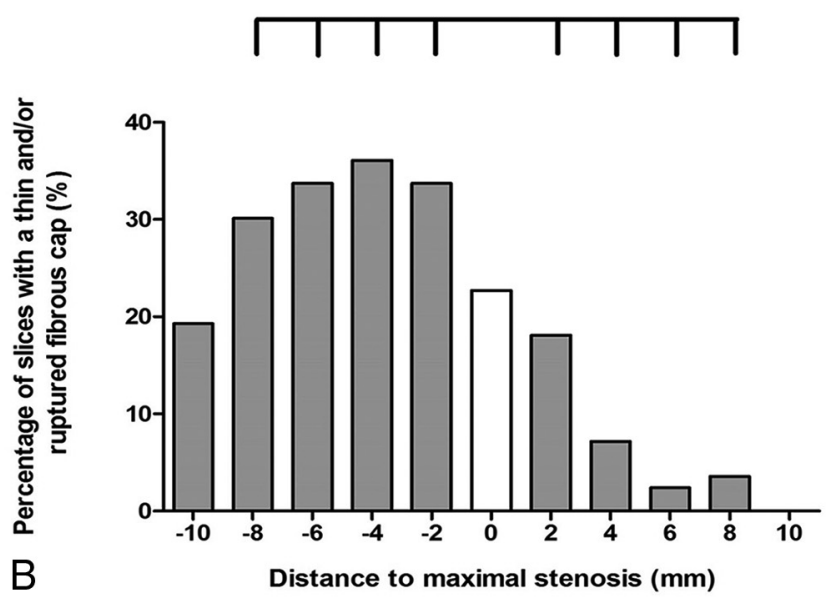

FIG 3. A, Histogram showing significantly larger mean IPH areas in the proximal region of the plaque compared with the distal region. Mean IPH area percentages are shown for each section in relation to the smallest lumen. The white bar indicates the section with the narrowest lumen (distance $=0 \mathrm{~mm}$ ), the bars on the left with the negative numbers are slices proximal (proximally), and the bars on the right with the positive numbers indicate the slices distal to the smallest lumen. Each section has a thickness of $2 \mathrm{~mm}$. An asterisk indicates a statistically significant difference $(P<.05)$ between the proximal and distal slices using a paired $t$ test. $B$, Prevalence of a TRFC plotted for each section position with respect to the section with the smallest lumen $(0)$. The bars on the left with the negative numbers are slices proximal, and the bars on the right with the positive numbers indicate the slices distal to the smallest lumen. An asterisk indicates a statistically significant difference $(P<.05)$ between the proximal and distal slices using a McNemar test.

Table 1: Differences in mean IPH area (\% of total vessel wall) between proximal and distal regions

\begin{tabular}{|c|c|c|c|c|}
\hline $\begin{array}{l}\text { Longitudinal Distance } \\
\text { from Section with } \\
\text { Smallest Lumen (mm) }\end{array}$ & $\begin{array}{l}\text { No. of Slices Where } \\
\text { Proximal and Distal } \\
\text { Sections Are Available }\end{array}$ & $\begin{array}{l}\text { Mean \% IPH with } \\
\text { Respect to Total Vessel } \\
\text { Wall Area in the } \\
\text { Proximal Region }\end{array}$ & $\begin{array}{c}\text { Mean \% IPH with } \\
\text { Respect to Total Vessel } \\
\text { Wall Area in the Distal } \\
\text { Region }\end{array}$ & $P$ Value \\
\hline 2 & 66 & $14.4(\mathrm{SD}, 1.9)$ & $9.6(\mathrm{SD}, 2.1)$ & .040 \\
\hline 4 & 59 & $14.7(\mathrm{SD}, 1.7)$ & $5.4(S D, 1.8)$ & $<.001$ \\
\hline 6 & 45 & $11.1(\mathrm{SD}, 1.6)$ & $2.2(\mathrm{SD}, 1.3)$ & .001 \\
\hline 8 & 39 & $7.5(\mathrm{SD}, 1.5)$ & $2.2(\mathrm{SD}, 1.5)$ & .056 \\
\hline 10 & 34 & $5.0(\mathrm{SD}, 1.4)$ & $1.1(\mathrm{SD}, 1)$ & .077 \\
\hline
\end{tabular}

Table 2: Differences in prevalence of a TRFC between proximal and distal regions

\begin{tabular}{lcccc}
\hline $\begin{array}{c}\text { Longitudinal Distance } \\
\text { from Section with } \\
\text { Narrowest Lumen (mm) }\end{array}$ & $\begin{array}{c}\text { No. of Slices Where } \\
\text { Proximal and Distal } \\
\text { Sections Are Available }\end{array}$ & $\begin{array}{c}\text { TRFC (No.) (\%) } \\
\text { Proximal Region }\end{array}$ & $\begin{array}{c}\text { TRFC (No.) (\%) } \\
\text { Distal Region }\end{array}$ & \begin{tabular}{c}
$\boldsymbol{P}$ Value \\
\hline 2
\end{tabular} \\
\hline & 63 & $28(33.7)$ & $6(18.1)$ & .007 \\
6 & 56 & $30(36.1)$ & $2(2.4)$ & .001 \\
8 & 43 & $28(33.7)$ & $3(3.6)$ & .001 \\
10 & 38 & $25(30.1)$ & 022 \\
\hline
\end{tabular}

prevalence of a TRFC was also higher in the proximal region; however, it was not significant $(19.3 \%$ versus $0 \% ; P=1.0)$ (Table 2). Overall, 66 (75\%) patients demonstrated a TRFC on the proximal side, while this number was $19(22 \%)$ on the distal side $(P<.001)$ (Fig 3B).

To investigate whether the position of the stenosis relative to the carotid bifurcation affects the distribution of intraplaque hemorrhage, we divided the patients into 2 groups, ie, $50 \%$ of the patients with the most distal position of the stenosis and $50 \%$ of the patients with the most proximal position. The median difference in the position of the narrowest lumen with respect to the bifurcation was $10 \mathrm{~mm}$ between these 2 groups. Both groups showed more IPH at the proximal side of the carotid plaque (data not shown).

\section{DISCUSSION}

The present study demonstrates larger mean IPH areas on the proximal region compared with the distal region of carotid plaques assessed with MR imaging in patients with TIA and stroke with mild-to-moderate carotid artery stenosis. Additionally, we found that TRFCs are more frequently located in the proximal region.

The higher prevalence of a TRFC on the proximal side of the plaques was also reported in a previous study with symptomatic and asymptomatic individuals. ${ }^{29}$ This could be caused by differences in 
the wall stress and wall shear stress between the upstream and downstream parts of the plaque. Similarly, increased prevalence of ulcerations in the proximal region of the carotid atherosclerotic plaque has been reported. ${ }^{30,31}$ The increased prevalence of a TRFC on the proximal side could be related to the increased amount of intraplaque hemorrhage in this region because IPH might also develop from the luminal side via fissures or rupture of the FC. ${ }^{17}$ A previous PARISK substudy has shown an association between the disrupted plaque surface and intraplaque hemorrhage on MR imaging. ${ }^{10}$

Previously, Fagerberg et $\mathrm{al}^{11}$ also described a higher incidence of severe carotid atherosclerotic lesions (containing IPH, macrophages, TRFC) proximal compared with distal in histopathologic specimens. Their population consisted of 40 patients scheduled for carotid endarterectomy with severe stenosis, while patients included in our analysis had a mild-to-moderate stenosis. Yilmaz et $\mathrm{al}^{29}$ and Dirksen et $\mathrm{al}^{32}$ also demonstrated significantly more macrophages and rupture sites at the proximal side in patients with carotid stenosis who underwent carotid endarterectomy. Yilmaz et al found an equal prevalence of intraplaque hemorrhage between the proximal and distal regions (22\% versus $23 \%$ ) in their study of symptomatic and asymptomatic patients with carotid endarterectomy with $>70 \%$ carotid stenosis. ${ }^{29}$ However, they did not investigate differences in the area of IPH. Our results also demonstrate that in a group of patients with a mild-to-moderate degree of stenosis in which the arterial pressure wave reflection is less severe, the proximal region still shows significantly more IPH. Thus, also in this population, biomechanical or hemodynamic factors may relate to IPH.

The larger areas of IPH on the proximal part of the plaque may be related to differences in wall stress, which is often increased in the proximal part of the plaque ${ }^{13-16}$ due to arterial pressure wave reflection at the stenosis. The local blood pressure is typically 3 orders of magnitude larger than wall shear stress ${ }^{33}$ and, therefore, is the dominant factor for plaque deformation and plaque rupture. ${ }^{34}$ A large population study, eg, the Rotterdam Study, demonstrated that pulse pressure, the driving force for plaque deformation, is the strongest determinant of IPH, independent of cardiovascular disease risk factors and other blood pressure components. ${ }^{35}$ Plaque deformation could lead to local tissue damage such as fissures in the FC or rupture of microvessels, causing development or progression of IPH. Most interesting, population studies also showed that pulse pressure is an independent predictor of coronary heart disease, ${ }^{35}$ cardiovascular mortality in men, ${ }^{36}$ multiple adverse cardiovascular outcomes, ${ }^{37}$ and stroke. ${ }^{38}$ The latter meta-analysis demonstrated that a relatively small increase in pulse pressure $(10 \mathrm{~mm} \mathrm{Hg})$ was associated with the occurrence of stroke. ${ }^{38}$ Therefore, studies have recently been advocated to assess therapies targeted at a reduction of pulse pressure. ${ }^{38}$

Previous studies have assessed plaque biomechanics using computational models with inherent assumptions. Most of these studies focused on plaque rupture rather than IPH development. ${ }^{39,40}$ Huang et $\mathrm{al}^{41}$ showed that by using an image-based computational model in 5 patients, the IPH is associated with higher structural wall stress. Teng et $\mathrm{al}^{42}$ demonstrated that by using a numeric model based on 4 surgery specimens, local tissue deformations were larger around microvasculature surrounded by red blood cells, indicative of IPH.
Wall stress is not to be confused with wall shear stress, caused by frictional (eg, hemodynamic) forces due to blood flow. Wall shear stress is usually also higher in the upstream region with laminar flow, while the turbulent flow downstream of the maximal stenosis is associated with low shear stress levels. ${ }^{11,12,14,33,43-47}$ High wall shear stress promotes apoptosis of vascular smooth-muscle cells. ${ }^{48}$ It also leads to an increased expression of endothelial adhesion molecules, resulting in an accumulation of macrophages, ${ }^{32}$ which will result in an increased amount of metalloproteinases, which can break down the matrix of the overlying FC and, therefore, contribute to destabilization of the plaque. ${ }^{12,30,32}$ This will tip the scale toward matrix breakdown instead of cap-reinforcing matrix synthesis by smooth-muscle cells. ${ }^{14}$ Thus, increased wall shear stress in the upstream region may lead to degradation of the FC, which can also contribute to the development of IPH.

A limitation of the present study is the lack of hemodynamic and biomechanical data (ie, the distribution of wall stress and wall shear stress). Computational fluid dynamics and 4D flow MR imaging can be used to determine wall stress and wall shear stress. ${ }^{46,47}$ Future studies are warranted that include computational fluid dynamics or $4 \mathrm{D}$ flow MR imaging to directly relate the local distribution of IPH and TRFC to wall stress and wall shear stress. If a causal relation is proved, it may lead to evaluation of new treatment options, such as pulse-pressure reduction.

Another limitation in the PARISK study is that different scanners and coils were used at different centers. Consequently, there were differences in the image quality of datasets coming from different centers.

\section{CONCLUSIONS}

We demonstrated that IPH is more prevalent on the proximal side of the plaque compared with the distal side in patients with mild-to-moderate stenosis. This prevalence may indicate that biomechanical and hemodynamic factors play an important role in the development of IPH. The results of our study suggest that radiologists could pay attention to whether they observe abnormal soft tissue in the proximal region of the plaque when reviewing carotid MRA and CTA examinations.

\section{ACKNOWLEDGMENTS}

Participating centers: Academic Medical Center, Amsterdam (P.J. Nederkoorn); Erasmus Medical Center, Rotterdam (A. van der Lugt, P.J. Koudstaal); Almere (M. Limburg); Kennemer Gasthuis, Haarlem (M. Weisfelt); Laurentius Ziekenhuis, Roermond (A.G. Korten); Maasstad Ziekenhuis, Rotterdam (R. Saxena); Maastricht University Medical Center (M.E. Kooi, R.J. van Oostenbrugge, W.H. Mess); Sint Antonius Ziekenhuis, Nieuwegein (S.C. Tromp); Sint Franciscus Gasthuis, Rotterdam (S.L.M. Bakker); Slotervaartziekenhuis, Amsterdam (N.D. Kruyt); Tergooi Ziekenhuizen, Hilversum/Blaricum (J.R. de Kruijk); University Medical Center Utrecht (J. Hendrikse, G.J. de Borst); Viecuri Medisch Centrum, Venlo (B.J. Meems); Vlietland Ziekenhuis, Schiedam (J.C.B. Verhey); IJsselland Ziekenhuis, Capelle a/day IJsel (A.D. Wijnhoud); Zuyderland, Sittard (N.P. van Orshoven)/Heerlen (A.H.C.M.L. Schreuder). 
Disclosure forms provided by the authors are available with the full text and PDF of this article at www.ajnr.org.

\section{REFERENCES}

1. Bentzon JF, Otsuka F, Virmani R, et al. Mechanisms of plaque formation and rupture. Circ Res 2014;114:1852-66 CrossRef Medline

2. Daemen MJ, Kooi ME. Intraplaque hemorrhage as a stimulator of episodic growth of advanced, but nonsymptomatic atherosclerotic lesions bridging the gap. JACC Cardiovasc Imaging 2009;2:1390-92 CrossRef Medline

3. Underhill HR, Yuan C, Yarnykh VL, et al. Arterial remodeling in [corrected] subclinical carotid artery disease. JACC Cardiovasc Imaging 2009;2:1381-89 CrossRef Medline

4. Gupta A, Baradaran H, Schweitzer AD, et al. Carotid plaque MRI and stroke risk: a systematic review and meta-analysis. Stroke 2013;44:3071-77 CrossRef Medline

5. Kwee RM, van Oostenbrugge RJ, Mess WH, et al. MRI of carotid atherosclerosis to identify TIA and stroke patients who are at risk of a recurrence. J Magn Reson Imaging 2013;37:1189-94 CrossRef Medline

6. Schindler A, Schinner R, Altaf N, et al. Prediction of stroke risk by detection of hemorrhage in carotid plaques: meta-analysis of individual patient data. JACC Cardiovasc Imaging 2019;13(2 Pt 2)395406 CrossRefMedline

7. Virmani R, Kolodgie FD, Burke AP, et al. Atherosclerotic plaque progression and vulnerability to rupture: angiogenesis as a source of intraplaque hemorrhage. Arterioscler Thromb Vasc Biol 2005;25:205461 CrossRef Medline

8. Falk E, Nakano M, Bentzon JF, et al. Update on acute coronary syndromes: the pathologist's view. Eur Heart J 2013;34:719-728 CrossRef Medline

9. Crombag G, Schreuder F, van Hoof RH, et al. Microvasculature and intraplaque hemorrhage in atherosclerotic carotid lesions: a cardiovascular magnetic resonance imaging study. J Cardiovasc Magn Reson 2019;21:15 CrossRef Medline

10. van Dijk AC, Truijman MT, Hussain B, et al. Intraplaque hemorrhage and the plaque surface in carotid atherosclerosis: the Plaque at Risk study (PARISK). AJNR Am J Neuroradiol 2015;36:2127- 33 CrossRef Medline

11. Fagerberg B, Ryndel M, Kjelldahl J, et al. Differences in lesion severity and cellular composition between in vivo assessed upstream and downstream sides of human symptomatic carotid atherosclerotic plaques. J Vasc Res 2010;47:221-30 CrossRef Medline

12. Cicha I, Worner A, Urschel K, et al. Carotid plaque vulnerability: a positive feedback between hemodynamic and biochemical mechanisms. Stroke 2011;42:3502-10 CrossRef Medline

13. Gao H, Long Q, Kumar Das S, et al. Study of carotid arterial plaque stress for symptomatic and asymptomatic patients. J Biomech 2011;44:2551-57 CrossRef Medline

14. Slager CJ, Wentzel JJ, Gijsen FJ, et al. The role of shear stress in the destabilization of vulnerable plaques and related therapeutic implications. Nat Clin Pract Cardiovasc Med 2005;2:456-64 CrossRef Medline

15. Wenk JF. Numerical modeling of stress in stenotic arteries with microcalcifications: a parameter sensitivity study. J Biomech Eng 2011;133:014503 CrossRef Medline

16. Thrysoe SA, Oikawa M, Yuan C, et al. Longitudinal distribution of mechanical stresses in carotid plaques of symptomatic patients. Stroke 2010;41:1041-43 CrossRef Medline

17. Daemen MJ, Ferguson MS, Gijsen FJ, et al. Carotid plaque fissure: an underestimated source of intraplaque hemorrhage. Atherosclerosis 2016;254:102-08 CrossRef Medline

18. Saba L, Yuan C, Hatsukami TS, et al; Vessel Wall Imaging Study Group of the American Society of Neuroradiology. Carotid Artery Wall Imaging: Perspective and Guidelines from the ASNR Vessel Wall Imaging Study Group and Expert Consensus Recommendations of the American Society of Neuroradiology. AJNR Am J Neuroradiol 2018;39:E9-31 CrossRef Medline

19. Truijman MT, Kwee RM, van Hoof RH, et al. Combined 18FFDG PET-CT and DCE-MRI to assess inflammation and microvascularization in atherosclerotic plaques. Stroke 2013;44:3568-70 CrossRef Medline

20. Ota H, Yarnykh VL, Ferguson MS, et al. Carotid intraplaque hemorrhage imaging at 3.0-T MR imaging: comparison of the diagnostic performance of three T1-weighted sequences. Radiology 2010;254:551-63 CrossRef Medline

21. Truijman MT, Kooi ME, van Dijk AC, et al. Plaque at Risk (PARISK): prospective multicenter study to improve diagnosis of high-risk carotid plaques. Int J Stroke 2014;9:747-54 CrossRef Medline

22. Kim S, Kwak HS, Hwang SB, et al. Dynamic change of carotid intraplaque hemorrhage volume in subjects with mild carotid stenosis. Eur J Radiol 2018;105:15-19 CrossRef Medline

23. Crombag G, Spronk HM, Nelemans P, et al. No association between thrombin generation and intra-plaque haemorrhage in symptomatic carotid atherosclerotic plaques: the Plaque at RISK (PARISK) study. Thromb Haemost 2018;118:1461-69 CrossRef Medline

24. Yuan C, Mitsumori LM, Ferguson MS, et al. In vivo accuracy of multispectral magnetic resonance imaging for identifying lipid-rich necrotic cores and intraplaque hemorrhage in advanced human carotid plaques. Circulation 2001;104:2051-56 CrossRef Medline

25. Takaya N, Yuan C, Chu B, et al. Association between carotid plaque characteristics and subsequent ischemic cerebrovascular events: a prospective assessment with MRI: initial results. Stroke 2006;37:81823 CrossRef Medline

26. Cappendijk VC, Cleutjens $\mathrm{KB}$, Heeneman $\mathrm{S}$, et al. In vivo detection of hemorrhage in human atherosclerotic plaques with magnetic resonance imaging. J Magn Reson Imaging 2004;20:105-10 CrossRef Medline

27. Kwee RM, van Oostenbrugge RJ, Mess WH, et al. Carotid plaques in transient ischemic attack and stroke patients: one-year follow-up study by magnetic resonance imaging. Invest Radiol 2010;45:803-09 CrossRef Medline

28. Kwee RM, van Engelshoven JM, Mess WH, et al. Reproducibility of fibrous cap status assessment of carotid artery plaques by contrastenhanced MRI. Stroke 2009;40:3017-21 CrossRef Medline

29. Yilmaz A, Lipfert B, Cicha I, et al. Accumulation of immune cells and high expression of chemokines/chemokine receptors in the upstream shoulder of atherosclerotic carotid plaques. Exp $\mathrm{Mol}$ Pathol 2007;82:245-55 CrossRef Medline

30. Lovett JK, Rothwell PM. Site of carotid plaque ulceration in relation to direction of blood flow: an angiographic and pathological study. Cerebrovasc Dis 2003;16:369-75 CrossRef Medline

31. de Weert TT, Cretier S, Groen HC, et al. Atherosclerotic plaque surface morphology in the carotid bifurcation assessed with multidetector computed tomography angiography. Stroke 2009;40:1334-40 CrossRef Medline

32. Dirksen MT, van der Wal AC, van den Berg FM, et al. Distribution of inflammatory cells in atherosclerotic plaques relates to the direction of flow. Circulation 1998;98:2000-03 CrossRef Medline

33. Gijsen FJ, Wentzel JJ, Thury A, et al. Strain distribution over plaques in human coronary arteries relates to shear stress. $A m J$ Physiol Heart Circ Physiol 2008;295:H1608-14 CrossRef Medline

34. Hoeks AP, Reesink KD, Hermeling E, et al. Local blood pressure rather than shear stress should be blamed for plaque rupture. J Am Coll Cardiol 2008;52:1107-08; author reply 1108-09 CrossRef, CrossRef Medline

35. Selwaness M, van den Bouwhuijsen QJ, Verwoert GC, et al. Blood pressure parameters and carotid intraplaque hemorrhage as measured by magnetic resonance imaging: the Rotterdam Study. Hypertension 2013;61:76-81 CrossRef Medline

36. Benetos A, Rudnichi A, Safar M, et al. Pulse pressure and cardiovascular mortality in normotensive and hypertensive subjects. Hypertension 1998;32:560-64 CrossRef Medline

37. Selvaraj S, Steg PG, Elbez Y, et al. Pulse pressure and risk for cardiovascular events in patients with atherothrombosis: from the REACH Registry. J Am Coll Cardiol 2016;67:392-403 CrossRef Medline 
38. Liu FD, Shen XL, Zhao R, et al. Pulse pressure as an independent predictor of stroke: a systematic review and a meta-analysis. Clin Res Cardiol 2016;105:677-86 CrossRef Medline

39. Holzapfel GA, Mulvihill JJ, Cunnane EM, et al. Computational approaches for analyzing the mechanics of atherosclerotic plaques: a review. J Biomech 2014;47:859-69 CrossRef Medline

40. Cardoso L, Weinbaum S. Changing views of the biomechanics of vulnerable plaque rupture: a review. Ann Biomed Eng 2014;42:41531 CrossRef Medline

41. Huang X, Teng Z, Canton G, et al. Intraplaque hemorrhage is associated with higher structural stresses in human atherosclerotic plaques: an in vivo MRI-based 3D fluid-structure interaction study. Biomed Eng Online 2010;9:86 CrossRef Medline

42. Teng Z, He J, Degnan AJ, et al. Critical mechanical conditions around neovessels in carotid atherosclerotic plaque may promote intraplaque hemorrhage. Atherosclerosis 2012;223:321-26 CrossRef Medline

43. Siegel JM, Markou CP, Ku DN, et al. A scaling law for wall shear rate through an arterial stenosis. J Biomech Eng 1994;116:446-51 CrossRef Medline
44. Stroud JS, Berger SA, Saloner D. Numerical analysis of flow through a severely stenotic carotid artery bifurcation. J Biomech Eng 2002;124:9-20 CrossRef Medline

45. Fukumoto Y, Hiro T, Fujii T, et al. Localized elevation of shear stress is related to coronary plaque rupture: a 3-dimensional intravascular ultrasound study with in-vivo color mapping of shear stress distribution. J Am Coll Cardiol 2008;51:645-50 CrossRef Medline

46. Tuenter A, Selwaness M, Arias Lorza A, et al. High shear stress relates to intraplaque haemorrhage in asymptomatic carotid plaques. Atherosclerosis 2016;251:348-54 CrossRef Medline

47. Zhang G, Zhang S, Qin Y, et al. Differences in wall shear stress between high-risk and low-risk plaques in patients with moderate carotid artery stenosis: a 4D flow MRI study. Front Neurosci 2021;15:678358 CrossRef Medline

48. Wang Y, Qiu J, Luo S, et al. High shear stress induces atherosclerotic vulnerable plaque formation through angiogenesis. Regen Biomater 2016;3:257-67 CrossRef Medline 